\title{
Mapa cultural de los instrumentos musicales y objetos sonoros de metal arqueológicos: idiófonos (Área Andina centro-meridional)
}

\author{
Mónica Gudemos \\ Etno-Arqueomusicología \\ Secretaría de Ciencia y Tecnología \\ Centro de Investigaciones de la Facultad de Filosofía y Humanidades \\ Universidad Nacional de Córdoba (Argentina) \\ mgudemos@gmail.com
}

Recibido: 17 de julio de 2013

Aceptado: 9 de septiembre de 2013

\section{RESUMEN}

Presentamos aquí parte del Mapa Cultural de los idiófonos metálicos andinos arqueológicos, diseñado en el marco del Proyecto Arqueomusicología Americana (UNC, CIFFyH, SeCyT). Esta breve síntesis, expuesta en el XVII Congreso Nacional de Arqueología Argentina (2010) y actualizada con los datos brindados por los recientes estudios sobre las tradiciones metalúrgicas de los Andes centro-meridionales, es nuestra modesta contribución al estudio de las dinámicas sociales en las que estos objetos estuvieron involucrados.

Palabras clave: Idiófonos metálicos, música prehispánica, campanas arqueológicas.

\section{Cultural Map of Archaeological Metal Musical Instruments and Sound Objects: Idiophones (South-Central Andean Area)}

\section{ABSTRACT}

In this paper we present a part of the Cultural Map of archaeological Andean metal idiophones, designed in the American Archaeomusicology Project (UNC, CIFFyH, SeCyT). This brief synopsis, exposed in the $17^{\text {th }}$ National Congress of Argentinian Archaeology (2010) and updated with data provided by recent studies of pre-Hispanic metallurgical traditions of the south-central Andes, is our modest contribution to the study of social relations in which these objects were involved.

Key words: Metal idiophones, pre-Hispanic music, archaeological bells.

Sumario: 1. Introducción. 2. Campanas piramidales. 3. Puntos de contacto, 1. 4. La supremacía tecnológica santamaría. 5. Puntos de contacto, 2. 6. La belleza de la variedad. 7. Consideraciones finales. 8. Referencia documental. 9. Referencias bibliográficas.

\section{Introducción}

Los idiófonos ${ }^{1}$ metálicos andinos (campanas, cascabeles, placas, etc.) presentan variedades morfológicas determinadas por patrones constructivos y estéticos regionalmente localizados. Tales variedades nos permiten diseñar el Mapa Cultural de estos objetos, atendiendo a sus centros de producción, dispersión geográfica y asimilación cultural $^{2}$. Dicho mapa, cuyo extracto aquí presentamos para los Andes Centro-Meri-

\footnotetext{
1 En éstos el sonido es producido por la materia misma del instrumento, sin recursos tales como la tensión de membranas o cuerdas.

2 Muchos de los materiales que analizamos carecen de datos contextuales. Por las características de este trabajo, hemos considerado sólo objetos con datos ciertos de procedencia.
} 
dionales, no pretende ser una carta geográfica de especies instrumentales, ni mucho menos una reducción global de aspectos culturales. Antes bien, se propone como un aporte para el estudio de las dinámicas sociales prehispánicas, en las que estos objetos estuvieron inmersos.

\section{Campanas piramidales ${ }^{3}$}

Esta tipología es la más difundida en los Andes Centro-Meridionales (Figuras 1, 2, 3 y Cuadros 1, 2 y 3). Para el Noroeste Argentino (NOA) los ejemplares registrados señalan el extremo sur de los Nevados del Aconquija como una de las principales zonas de producción temprana, en contextos culturales Condorhuasi y Ciénaga (200 a. C.-500 d.C.). Ello estaría de acuerdo con lo observado por Luis González (2007: 34) respecto a que la disponibilidad de los depósitos naturales de minerales de cobre allí existentes habría favorecido el desarrollo de actividades metalúrgicas en la región desde épocas muy tempranas. Estilísticamente, el diseño de estos idiófonos ya habría sido concebido en su factura básica: una plancha cuadrangular perforada para suspensión. Lo interesante es que algunos ejemplares ciénaga del Período Temprano presentan concavidades hechas ex profeso (A. González 1979; Gudemos 1998b, 2001), que no son el resultado fortuito de la perforación percutida, sino de posibles búsquedas sonoras determinadas, que acusarían el conocimiento de principios acústicos básicos ${ }^{4}$.

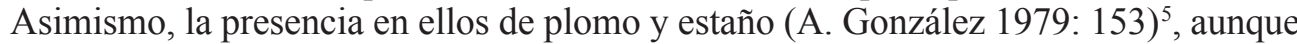
en pequeños porcentajes, indicaría el agregado cultural de elementos que favorecerían el proceso de colada y otorgarían mayor dureza y «brillantez tímbrica» a las planchas de cobre. Estas particularidades técnicas de carácter local se desarrollarían en el NOA para la producción de estas campanillas desde comienzos de la era, antes incluso que en otras regiones circundantes, pero contemporáneamente, creemos, a los procedimientos de fundición de cobre utilizados en el Norte Grande de Chile, hacia finales del Formativo Tardío (500 a.C.-300 d.C.), precisamente en la Quebrada de Guatacondo (Graffam et al. 1997). En esta época dichas actividades de producción habrían sido alentadas no sólo por una mayor estabilidad política y un crecimiento económico locales, sino también por una mayor dinámica de intercambio promovida por las redes sociales a larga distancia (Núñez 2005). A propósito, la producción metalúrgica local de bienes suntuarios ${ }^{6}$ que se daría hacia finales del Formativo Tardío en San Pedro de Atacama (Llagostera 1996; Núñez 2006) habría sido posteriormente «desplazada hacia un rol distinto, más vinculado con la producción de instrumentos funcionales» (Salazar et al. 2011: 141), por una dinámica social que promovió la importación de objetos metálicos producidos en regiones altiplánicas y transcordilleranas. Esta dinámica

\footnotetext{
3 Taxonomía numérica 111.242.122 (campanas independientes, colgantes con badajo). 112.1 [1] (cuando son utilizadas como cápsulas de sonaja para producir sonido por entrechoque).

4 La línea de plegamiento de las campanillas piramidales suele constituir también un rasgo estético distintivo de carácter local (Figura 3), como observamos en anteriores trabajos (Gudemos 1998b).

5 Ver análisis del ejemplar $\mathrm{N}^{\circ} 10463$ (Ciénaga III) en A. González 1979: 153. Véase también al respecto Arellano López (1982) y L. González (2007).

6 Entre los que estaría esta tipología de campanas (Gudemos ms.).
} 
Figura 1: Mapa cultural de idiófonos andinos centromeridionales, parte 1 (véase

el Cuadro 1). Dibujos y

fotografías: M. Gudemos.

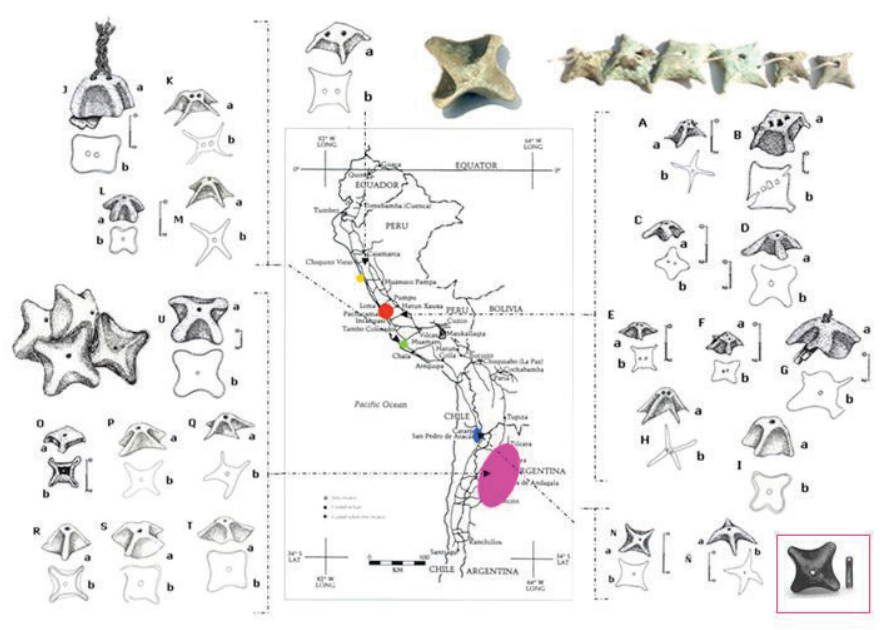

Cuadro 1: Idiófonos de la Figura 1

\begin{tabular}{|c|c|c|}
\hline Identificación en la figura & Identificación y procedencia & Localización \\
\hline A & VA 40911 (Pachacámac) & EM \\
\hline B & VA 40554 (Pachacámac) & EM \\
\hline $\mathrm{C}$ & VA 40912 (Pachacámac) & EM \\
\hline $\mathrm{D}$ & VA 40916 (Pachacámac) & EM \\
\hline $\mathrm{E}$ & VA 40913 (Pachacámac) & EM \\
\hline $\mathrm{F}$ & VA 40915 (Pachacámac) & EM \\
\hline G & VA 43351 (Pachacámac) & EM \\
\hline $\mathrm{H}$ & VA 40910 (Pachacámac) & EM \\
\hline I & VA 43304c (Pachacámac) & EM \\
\hline $\mathrm{J}$ & VA 45898 (Ica) & EM \\
\hline $\mathrm{K}, \mathrm{M}$ & VA 45893 (Ica) & EM \\
\hline $\mathrm{L}$ & VA 45892 (Ica) & EM \\
\hline $\mathrm{N}$ & * (Región Atacameña) & MGLP \\
\hline$\tilde{\mathrm{N}}$ & * (Región Atacameña) & MGLP \\
\hline $\mathrm{O}$ & VC 1628 (Río del Inca) & EM \\
\hline $\mathrm{P}$ & VC 4716 (Salta) & EM \\
\hline Q & N² 2874 S7/V6 (Juella) & MEC \\
\hline $\mathrm{R}$ & VC 4626 (Salta?) & EM \\
\hline $\mathrm{S}$ & VC 9252 (Salta?) & EM \\
\hline $\mathrm{T}$ & VC 1554 (Río del Inca) & EM \\
\hline $\mathrm{U}$ & VC 4715 (Río del Inca) & EM \\
\hline V & Grupo de 4 campanas (El Morro, Jujuy) & Debenedetti 1910: 227 \\
\hline Fotografía arriba, centro & Campanilla piramidal s/n (Región Atacameña) & MGLP \\
\hline Fotografía arriba, derecha & $\begin{array}{l}\text { Cápsulas piramidales ensartadas s/n (Región } \\
\text { Atacameña) }\end{array}$ & MGLP \\
\hline Arriba, izquierda & $\begin{array}{l}\text { Dibujo de una de las } 12 \text { campañillas piramidales } \\
\text { en conjunto VA13482 (Chimbote); } 20 \mathrm{~mm} \text { en su } \\
\text { línea diagonal. }\end{array}$ & EM \\
\hline $\begin{array}{l}\text { Margen inferior derecho } \\
\text { (recuadro) }\end{array}$ & $\begin{array}{l}\text { Ejemplar de bronce con badajo s/n (Catamarca); } \\
40 \mathrm{~mm} \text { en su línea diagonal. }\end{array}$ & MAQ \\
\hline
\end{tabular}

* Sin número de identificación en el momento del registro efectuado en esta investigación. 

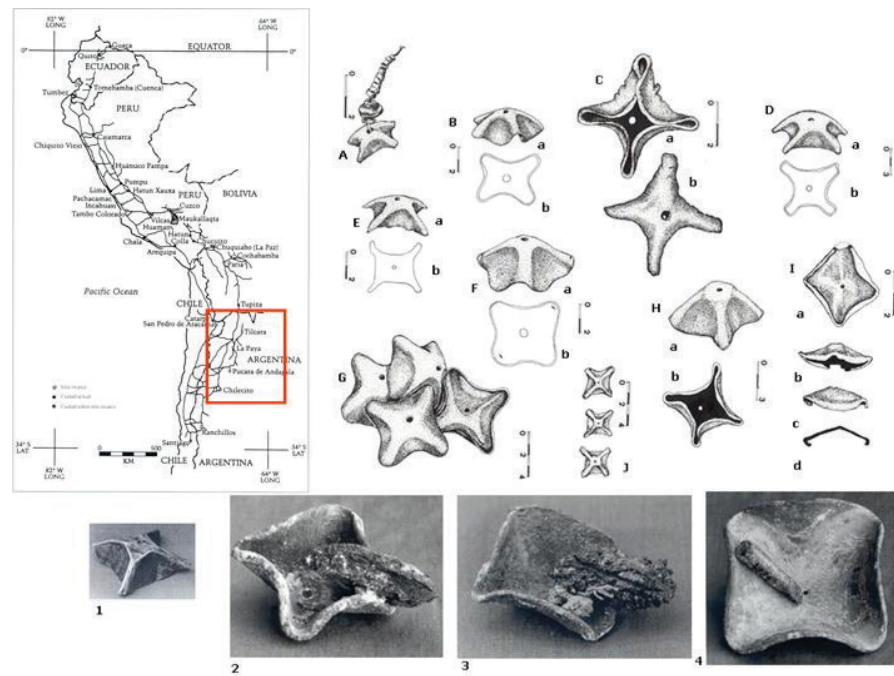

Figura 2: Mapa cultural de idiófonos andinos centromeridionales, parte 2 (véase el Cuadro 2). Dibujos y fotografías: M. Gudemos.

Cuadro 2: Idiófonos de la Figura 2

\begin{tabular}{lll}
\hline Id. en fig. & \multicolumn{1}{c}{ Identificación y procedencia } & \multicolumn{1}{c}{ Localización } \\
\hline A & Campanilla piramidal (Pucará de Rinconada, Jujuy) & Boman 1991: 648-649 \\
B & Campanilla piramidal No 3226 (Los Amarillos, Jujuy) & MEC \\
C & Campanilla piramidal (Puna Jujeña, NOA) & Casanova 1938: 441 \\
D & Campanilla piramidal No 4364 (Huacalera, Jujuy) & MEC \\
E & Campanilla piramidal No 2874 (Juella, Jujuy) & MEC \\
F & Campanilla piramidal No 412 (Angualasto, San Juan) & MEC \\
G & 4 campanillas piramidales (El Morro, Jujuy) & Debenedetti 1910: 226-227 \\
H & Campanilla piramidal No 1578 (Doncellas, Jujuy) & MEC \\
I & Campanilla piramidal No 9152 (Ciénaga, Catamarca) & MLP. González 1979: 153 \\
J & Pequeñas campanillas piramidales [cápsulas de sonaja] (El & Debenedetti 1910: 227 \\
& Morro, Jujuy) & \\
1 & Pequeña campanilla piramidal [cápsula de sonaja] No 4388 & MEC \\
& (Huacalera, Jujuy) & MEC \\
2 & Campanilla piramidal * (La Falda, Tilcara, Jujuy) & MEC \\
3 & Campanilla piramidal * (La Falda, Tilcara, Jujuy) & MEC \\
4 & Campanilla piramidal No 4221 (San José, Tilcara, Jujuy) & MEC \\
\hline * Sin número de identificación en el momento del registro efectuado en esta investigación.
\end{tabular}

puede ser claramente observada a través de la «movilidad» de determinados idiófonos metálicos, con lineamientos estilísticos particulares.

Según nuestros registros (Gudemos ms.), para esta tipología y en periodos más tardíos, el martillado en frío de las planchas de base cobre les otorgó dureza, pero les quitó elasticidad. Se aumentó su cualidad, modificando la estructura interna del metal, pero se las llevó a un punto de fisura (González y Buono 2007: 184), tal como constatamos en algunos ejemplares de Tarija, San Pedro de Atacama, Molinos, Puna y Quebrada de Humahuaca ${ }^{7}$. Posiblemente, para evitar el punto de fisura se trató de

7 Específicamente nos referimos a los ejemplares de: San Pedro de Atacama ( $\mathrm{N}^{\circ} 115$, Norte de Chile [MEC]), Molinos ( $\mathrm{N}^{\circ} 748$, Salta [MEC]), Queta (Boman 1992: 616) y Casabindo (VA 11346, Puna de Jujuy [EM]), Coiruro ( $\mathrm{N}^{\circ}$ 
Figura 3: Mapa cultural de idiófonos andinos centromeridionales, parte 3 (véase el Cuadro 3). Dibujos y fotografías: M. Gudemos.

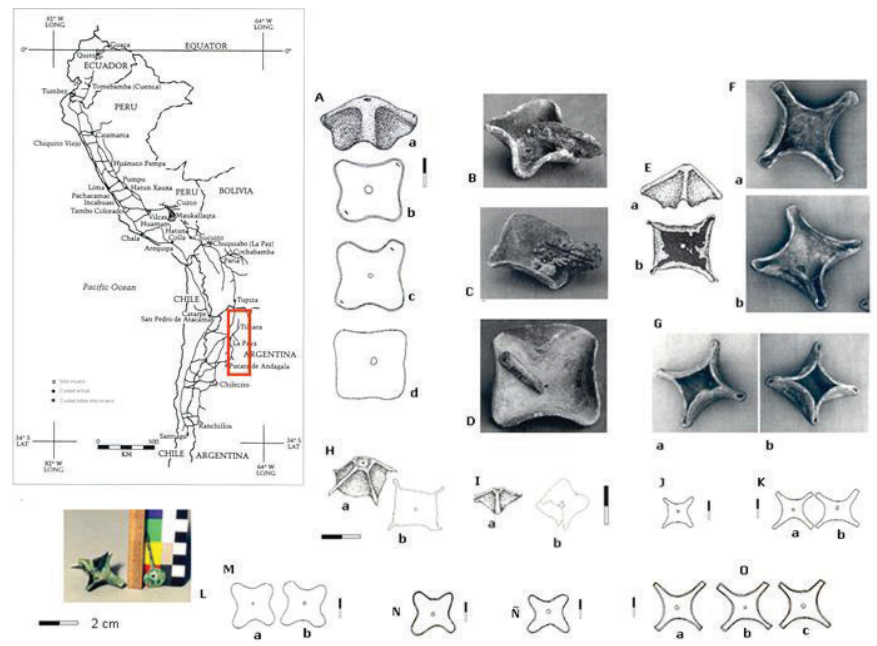

Cuadro 3: Idiófonos de la Figura 3

\begin{tabular}{|c|c|c|}
\hline Id. en fig. & Identificación y procedencia & Localización \\
\hline A a & Campanilla piramidal N 412 (Angualasto, San Juan). & MEC \\
\hline $\mathrm{Ab}$ & $\begin{array}{l}\text { Campanilla piramidal N } 2445 \text { (Pucará de Tilcara, Jujuy). Detalle de } \\
\text { contorno de base. }\end{array}$ & MEC \\
\hline Ac & Detalle de contorno de base del ejemplar A a, $N^{\circ} 412$ & MEC \\
\hline Ad & $\begin{array}{l}\text { Campanilla piramidal N }{ }^{\circ} 2142 \text { (Pucará de Tilcara, Jujuy). Detalle de } \\
\text { contorno de base. }\end{array}$ & MEC \\
\hline B & Campanilla piramidal $*($ La Falda/Tilcara $)$ & MEC \\
\hline $\mathrm{C}$ & Campanilla piramidal $*$ (La Falda/Tilcara) & \\
\hline $\mathrm{D}$ & Campanilla piramidal N 4221 (San José, Tilcara, Jujuy) & MEC \\
\hline $\mathrm{E}$ & Campanilla piramidal N ${ }^{\circ} 748$ (Molinos, Salta) & MEC \\
\hline $\mathrm{F} a, \mathrm{~b}$ & Campanillas piramidales $\mathrm{N}^{\circ} 4362$ y $\mathrm{N}^{\circ} 4363$ (Huacalera, Jujuy) & MEC \\
\hline $\mathrm{Ga}, \mathrm{b}$ & Campanillas piramidales $N^{\circ} 3304$ y No 3886 (Doncellas, Jujuy) & MEC \\
\hline $\mathrm{H}$ & Campanilla piramidal $N^{\circ} 4388$ (Huacalera, Jujuy) & MEC \\
\hline I & Campanilla piramidal $N^{\circ} 115$ (San Pedro de Atacama) & MEC \\
\hline $\mathrm{J}$ & Campanilla piramidal $N^{\circ} 2874$ (Juella, Jujuy) & MEC \\
\hline $\mathrm{K} a, \mathrm{~b}$ & Campanillas piramidales $N^{\circ} 3304$ y N 3886 (Doncellas, Jujuy) & MEC \\
\hline $\mathrm{L}$ & $\begin{array}{l}\text { Campanilla piramidal VA } 11346 \text { (Pueblo Viejo, Quebrada de Tucute, } \\
\text { Jujuy) }\end{array}$ & EM \\
\hline $\mathrm{Ma}, \mathrm{b}$ & Campanillas piramidales $\mathrm{N}^{\circ} 1576$ y N 1578 (Doncellas, Jujuy) & MEC \\
\hline $\mathrm{N}$ & Campanilla piramidal Nº 3226 (Los Amarillos, Jujuy) & MEC \\
\hline$\tilde{\mathrm{N}}$ & Campanilla piramidal № 2985 (La Isla, Jujuy) & MEC \\
\hline $\mathrm{O} a, \mathrm{~b}, \mathrm{c}$ & Campanillas piramidales $\mathrm{N}^{\circ} 4362, \mathrm{~N}^{\circ} 4363$ y $\mathrm{N}^{\circ} 4364$ (Huacalera, Jujuy) & MEC \\
\hline
\end{tabular}

* Sin número de identificación en el momento del registro efectuado en esta investigación.

mantener la maleabilidad de las planchas, sometiéndolas a temperaturas entre los $400^{\circ}$ y $500^{\circ} \mathrm{C}$, perjudicando así su dureza.

Los constructores ya sabrían que a mayor regularidad en la concavidad del vaso de campana mejor calidad sonora y que la tesitura y brillantez del sonido dependían tanto de

2371, Quebrada de Humahuaca, Jujuy [MEC], Tarija (VA 30595a [EM]). Véase Gudemos 1998a, 1998b, 2001, 2006. 
las dimensiones del vaso como de la dureza y el espesor de la plancha. Comprendemos la significación que el uso de los objetos metálicos tuvo en la parafernalia emblemática andina, pero no podemos soslayar las mejoras respecto de las características acústicas que se operó paulatinamente en el NOA para estos idiófonos, específicamente en el marco cultural de La Aguada (450-900 d.C.). En este caso el concepto de lo utilitario, aplicado aquí a las condiciones acústicas, no fue ajeno a las demandas de élite. Hablaríamos entonces del sonido mismo manejado conceptualmente como distintivo de clase.

Entre los siglos XII y XV las cualidades acústicas de los materiales y el diseño de estas campanas mejoraron sustancialmente en el NOA, siendo superiores a las procedentes de la Región Atacameña, sur de Bolivia e incluso el sur de Perú. Particularmente, una variedad de bronce fundida ya en su forma definitiva, compañera temporal y regional de las grandes campanas de bronce santamaría, se difundió en el NOA, aunque no en forma masiva. Registramos ejemplares de alta calidad, algunos con las típicas perforaciones en dos de sus puntas sobre una misma diagonal, excavados en Angualasto, Pucará de Tilcara, El Morro, San José de Tilcara, Río del Inca y Santa María (véanse ejemplos en Figura 2 y Cuadro 2 (F); Figura 3 y Cuadro 3 (A, $\mathrm{a}, \mathrm{b}, \mathrm{c})$. Esta variedad habría estado provista de badajos forjados ${ }^{8}$. Como dijimos en anteriores trabajos, algunos diseños de plegado constituyeron aspectos morfológicos y estéticos de carácter local claramente individualizados.

En la época de contacto hispano-indígena esta tipología de campanas de base cobre continuó fabricándose con tecnología local indígena y utilizándose como objeto emblemático (Gudemos 1998b) ${ }^{9}$. En Tilcara, Quebrada de Humahuaca, se excavaron dos ejemplares de cobre, cuyas planchas fueron plegadas en forma semejante, mientras que sus badajos habrían sido construidos, aparentemente, con un trozo de hierro forjado de procedencia hispánica (Figura 2, abajo: 2, 3). En época colonial aún se fundían campanas de este tipo, con morfología indígena, como la de bronce de la colección Wolff, publicada en 1904 por Ambrosetti.

\section{Puntos de contacto, 1}

A juzgar por la dispersión geográfica de las campanillas metálicas, la Quebrada de Humahuaca habría constituido desde épocas Tiahuanaco y, particularmente, PostTiahuanaco una interesante vía de comunicación interregional. Determinadas tipologías como las pequeñas campanillas capsulares de oro procedentes de la Región Atacameña, de ascendencia cultural Tiahuanaco y posible difusión Mollo, excavadas en sitios quebradeños como Huacalera y San José de Tilcara, son claramente identificables (Figura 4 y Cuadro 4: G, H; Figura 5 y Cuadro 5: J, K). Asimismo, se identifican las tipologías cusqueña y valliserrana.

\footnotetext{
8 Alicia Soria Muñoz (Ciencias Químicas, Universidad Complutense de Madrid), comunicación personal. Tal el caso del ejemplar de San José (Figuras 2 y 4, Cuadros 2 y 4; Figura 3 y Cuadro 3: D) y del badajo procedente de Quilmes (VC 6692 [EM]) (Gudemos ms.).

9 La situación de hallazgo de una de estas campanillas en la mano derecha de un joven de élite (Figura 4 y Cuadro 4: B, C), indicaría su uso emblemático.
} 
Figura 4: Mapa cultural de idiófonos andinos centro-meridionales, parte 4 (véase el Cuadro

4). Dibujos y fotografías: M. Gudemos.
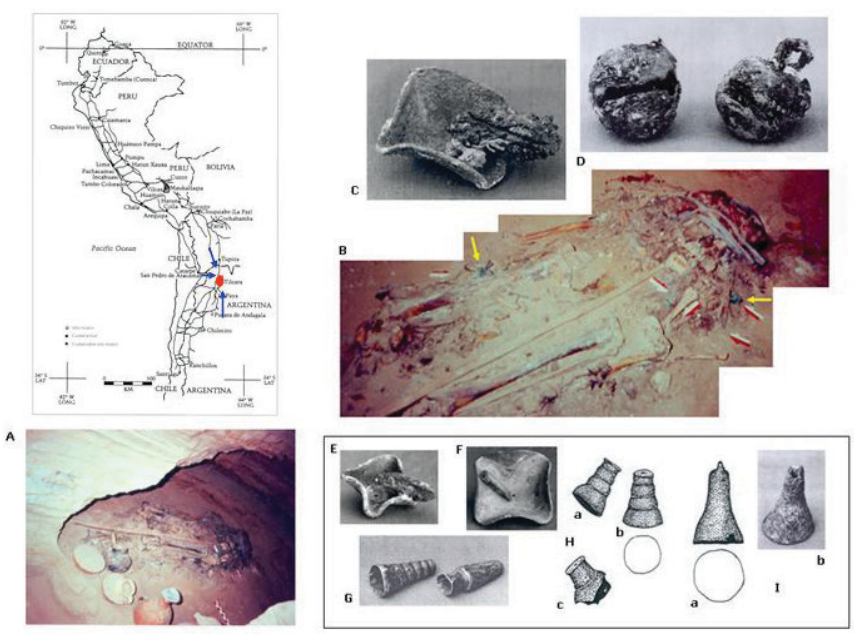

Cuadro 4: Idiófonos de la Figura 4

\begin{tabular}{|c|c|c|}
\hline Id. en fig. & Identificación y procedencia & Localización \\
\hline $\mathrm{A}, \mathrm{B}$ & $\begin{array}{l}\text { Contexto funerario excavado por O. Mendonça en La Falda, } \\
\text { Tilcara (Jujuy) en } 1996 .\end{array}$ & Fotos: Gudemos \\
\hline $\mathrm{C}$ & $\begin{array}{l}\text { Campana piramidal hallada en dicho contexto, en la mano derecha } \\
\text { del individuo joven, masculino (ver flecha) }\end{array}$ & MEC \\
\hline $\mathrm{D}$ & $\begin{array}{l}\text { Cascabeles hallados en el mismo contexto, próximos al cuello del } \\
\text { individuo (ver flecha) }\end{array}$ & MEC \\
\hline $\mathrm{E}$ & Campana piramidal $*$ (La Falda, Tilcara, Jujuy) & MEC \\
\hline $\mathrm{F}$ & Campana piramidal Nº 4221 (San José, Tilcara, Jujuy) & MEC \\
\hline G & $\begin{array}{l}\text { Cápsulas de sonaja cónicas N } 3609 \text { y N } 3610 \text { (San José, Tilcara, } \\
\text { Jujuy) }\end{array}$ & MEC \\
\hline $\mathrm{H} \mathrm{a}, \mathrm{b}, \mathrm{c}$ (frag.) & Cápsulas de sonaja cónicas (Pucará de Tilcara, Jujuy) & Casanova 1930 \\
\hline I & Campanita cónica Nº 214 (Pucará de Tilcara, Jujuy) & MEC \\
\hline
\end{tabular}

* Sin número de identificación en el momento del registro efectuado en esta investigación.

El laboreo por laminación, bateado y repujado de los pequeños idiófonos de oro es notable. Aparentemente, el principal punto de irradiación cultural Mollo habría sido la rica zona aurífera circumtiticaca de Tipuani y Guanay (Arellano 1982). Las pequeñas cápsulas cónicas de oro con sus característicos diseños, propios de una $f a$ bricación en serie ${ }^{10}$, son en la Quebrada de Humahuaca y Región Atacameña objetos foráneos, que corroborarían las observaciones de Tarragó (2006). En efecto, estos objetos pequeños de valor simbólico y suntuario, de escaso volumen y consumo no masivo, habrían recorrido grandes distancias, pero en pequeñas cantidades. Esta tipología habría sido de uso exclusivo de élite, como lo indicaría el ajuar de San Pedro de Atacama que mostramos en la Figura 5:I (los dos ejemplares capsulares en detalle ampliado). Según recientes estudios, aparentemente, en la Quebrada de Humahuaca en tiempos preincaicos tardíos «la circulación del oro (metal u objetos) se desarrolló

10 En Gudemos (1998a, 1998b, 2001) presentamos tablas con datos de mediciones que acusan una gran sistematización constructiva. 


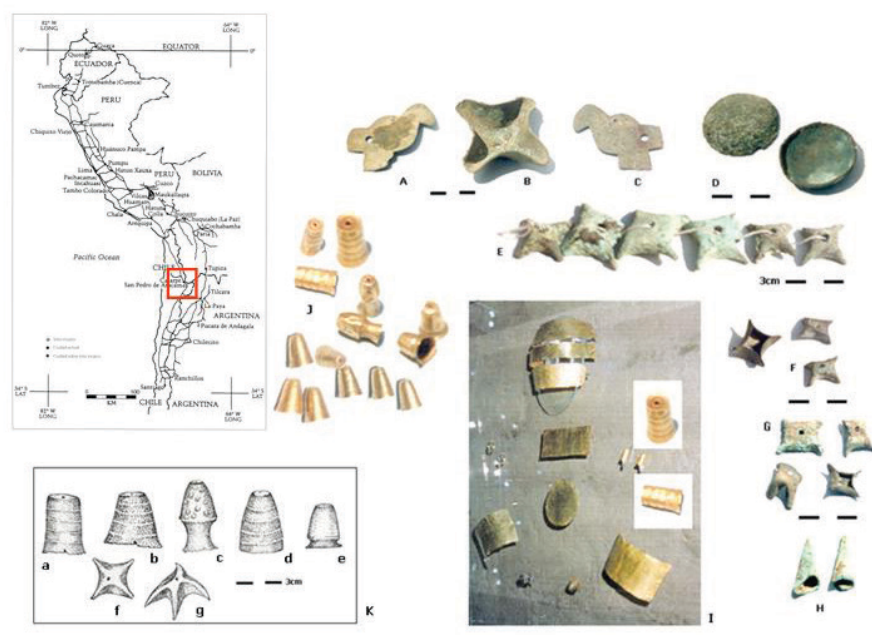

Figura 5: Mapa cultural de idiófonos andinos centromeridionales, parte 5 (véase el Cuadro 5). Dibujos y fotografías: M. Gudemos.

Cuadro 5: Idiófonos de la Figura 5

\begin{tabular}{lll}
\hline Id. en fig. & \multicolumn{1}{c}{ Identificación y procedencia } & Localización \\
\hline A-C & Idiófonos* (Región Atacameña) & MGLP \\
B & Campanita piramidal* (Región Atacameña) & MGLP \\
D & Posibles mitades de sonajero bivalvo* (Quitor 6, Región Atacameña) & MGLP \\
E & Cápsulas de sonaja ensartada* (Coyo Oriental) & MGLP \\
F & Cápsulas de sonaja* (Coyo Oriental) & MGLP \\
G & Cápsulas de sonaja* (Tchecar) & MGLP \\
H & Cápsulas de sonaja cónicas* (Tchecar) & MGLP \\
& $\begin{array}{l}\text { Placas y 2 cápsula de sonajas troncocónicas de oro (vistas con aumento } \\
\text { I }\end{array}$ & MGLP recuadros) de un ajuar funerario* (Región Atacameña) \\
J & Cápsulas de sonaja cónicas y troncocónicas de oro* (Región & MGLP \\
& Atacameña) & \\
K & Tipologías de cápsulas de sonajas de oro* (Región Atacameña) & MGLP \\
\hline
\end{tabular}

* Sin número de identificación en el momento del registro efectuado en esta investigación.

bajo un cierto control, por circuitos diferentes» (Angiorama 2011: 7). Lo mismo habría sucedido posteriormente con las típicas campanillas cónicas de cobre y bronce de tradición cusqueña (Figura 6 y Cuadro 6) ${ }^{11}$, de amplia dispersión geográfica en todo el Mundo Andino, mas no en forma masiva, durante la administración incaica. Una de las «niñas del Llullaillaco», conocida como la doncella, las poseía pendiendo de su cuello. Particularmente en este caso, las dos campanitas metálicas responden en sus diseños a los estudiados por nosotros procedentes de la región circumtiticaca, específicamente Tiahuanaco y Hachirí (Gudemos ms.) ${ }^{12}$.

11 Taxonómicamente, los ejemplares más pequeños de esta tipología son cápsulas de sonaja de producción sonora por entrechoque: 112.1 [1]. Sin embargo, se registraron pequeños badajos en algunos ejemplares.

12 Como referencia de lo observado, en nuestras bases de datos de los materiales estudiados en el Ethnologisches Museum de Berlín, registramos los ejemplares VA 2789, VA 10501, VA 10824, VA 10825, VA 10826, VA 10827, VA 10828 (todos procedentes de Tiahuanaco) y VA 10954 (de Hachirí). 
Figura 6: Mapa cultural de idiófonos andinos centromeridionales, parte 6 (véase el Cuadro 6). Dibujos y fotografías: M. Gudemos.

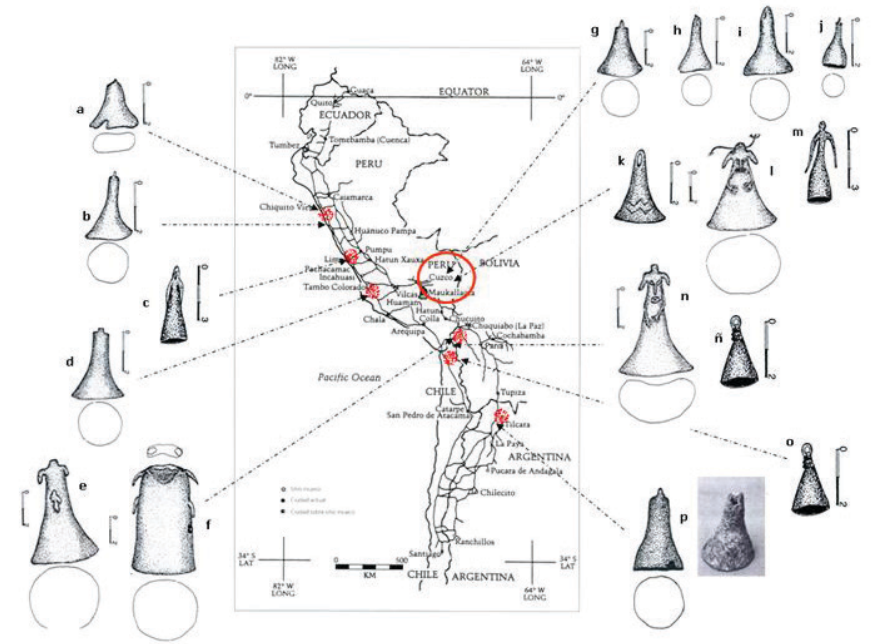

Cuadro 6: Idiófonos de la Figura 6

\begin{tabular}{lll}
\hline Id. en fig. & \multicolumn{1}{c}{ Identificación y procedencia } & Localización \\
\hline $\mathrm{a}$ & Campanita cónica VA 2445 (Casma Huaraz) & EM \\
$\mathrm{b}$ & Campanita cónica VA 1337 (Huacho) & EM \\
$\mathrm{c}$ & Campanita cónica VA 37489 (ca. Lima) & EM \\
$\mathrm{d}$ & Campanita cónica VA 16045 (San Ramón) & EM \\
$\mathrm{e}$ & Campana cónica VA 12404 (Omasuyu) & EM \\
$\mathrm{f}$ & Campana troncocónica VA 12664 (Omasuyu) & EM \\
$\mathrm{g}$ & Campanita cónica VA 8790 (Cusco) & EM \\
$\mathrm{h}$ & Campanita cónica VA 2873b (Cusco) & EM \\
$\mathrm{i}$ & Campanita cónica VA 8789 (Cusco) & EM \\
$\mathrm{j}$ & Campanita cónica VA 8792 (Cusco) & EM \\
$\mathrm{k}$ & Campanita cónica VA 8693 (Cusco) & EM \\
$\mathrm{l}$ & Campanita cónica VA 8716 (Cusco) & EM \\
$\mathrm{m}$ & Campanita cónica VA 8713 (Cusco) & EM \\
$\mathrm{n}$ & Campanita cónica VA 12796 (Huaqui) & EM \\
$\tilde{n}$ & Campanita cónica VA 10954 (Tiahuanaco) & EM \\
$\tilde{n}$ derecha & Campana troncocónica VA 65946 (Jahuerja, Puno) & EM \\
o & Campanita cónica VA 10825 (Hachirí) & EM \\
$\mathrm{p}$ & Campanita cónica N ${ }^{\circ}$ 2140 (Pucará de Tilcara, Jujuy) & MEC \\
\hline
\end{tabular}

\section{La supremacía tecnológica santamaría}

Las grandes campanas santamaría de bronce son, sin duda, una de las expresiones artísticas, tecnológicas y simbólicas más importantes del mundo andino prehispánico. El sistema de vaciado, el porcentaje de estaño y las considerables dimensiones ${ }^{13}$ indican una mano de obra altamente especializada, tanto como las exigencias de su demanda (Gudemos 1998b, 2001, 2006). Por envergadura y material estas campanas permiten una producción

13 Con un porcentaje de Sn entre el 2,5 y el 11\%, aprox. Dimensiones: ca. $30 \mathrm{~cm}$ de altura y $3,7 \mathrm{~kg}$ en sus valores máximos. 

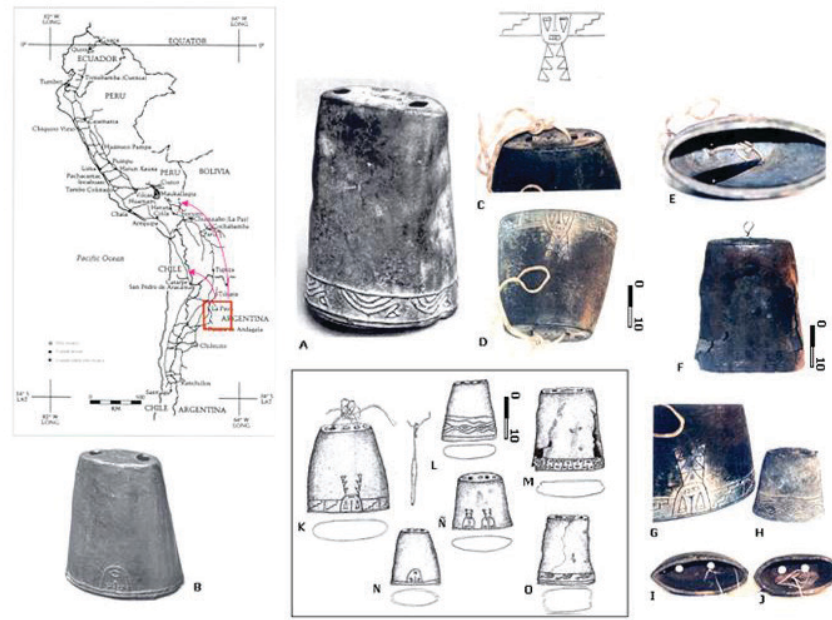

Figura 7: Mapa cultural de idiófonos andinos centromeridionales, parte 7 (véase el Cuadro 7). Dibujos y fotografías: M. Gudemos.

Cuadro 7: Idiófonos de la Figura 7

\begin{tabular}{lll}
\hline \multicolumn{1}{c}{ Id. en fig. } & \multicolumn{1}{c}{ Identificación y procedencia } & \multicolumn{1}{c}{ Localización } \\
\hline $\mathrm{A}, \mathrm{O}$ & Campana troncocónica s/oval N ${ }^{\circ}$ 687 (Salta?) & MEC \\
$\mathrm{B}, \mathrm{N}$ & Campana troncocónica s/oval N 685 (Salta?) & MEC \\
$\mathrm{C}, \mathrm{D}, \mathrm{E}, \mathrm{G}, \mathrm{K}$ & Campana troncocónica s/oval VC 1311a (Curtiembre) & EM \\
$\mathrm{F}, \mathrm{M}$ & Campana troncocónica s/oval VC 1312 (Carril) & EM \\
$\mathrm{H}, \mathrm{L}$ & Campana troncocónica s/oval VC 4717 (Salta) & EM \\
$\mathrm{I}$ & Campana troncocónica s/oval VC 4718 (Salta) & EM \\
$\mathrm{J}$ & Campana troncocónica s/oval VC 1289 (Animaná) & EM \\
$\tilde{\mathrm{N}}$ & Campana troncocónica s/oval VC 4719 (Salta?) & EM \\
\hline
\end{tabular}

sonora importante, aunque no precisamente de calidad. El vaso achatado de sección oval de estas campanas, la casi perpendicularidad entre la línea de base y la línea de pared, las grandes perforaciones para suspensión y, en muchos casos, la falta de densidad regular en la distribución de material en su estructura, por las junturas propias del vaciado en moldes de varios cuerpos, atentan contra una buena propagación de las vibraciones a través de su cuerpo. Las marcas de percusión son visibles tanto por fuera como por dentro, pudiéndose incluso a través de ellas estimarse en casos determinados el tipo y la dimensión de la superficie de golpe. Algunos ejemplares han sido percutidos hasta el punto de fractura y desprendimiento de material (Figura 7 y Cuadro 7: A, F, M, O). La iconografía de estos idiófonos presenta cabezas trofeo, suris y guardas serpentiformes. La función social de su sonido tuvo sin duda una particular importancia ritual. Su estrecha relación estética, tanto en su naturaleza iconográfica como material, con los discos y hachas ceremoniales adscribe estos idiófonos a un contexto de élite determinado. A todos los atributos simbólicos del metal y el sonido, debe sumarse el de la dinámica de cambio, esto es, la transformación activa de su iconografía. En efecto, la función de estos objetos permite que los diseños sean observados en posición durante el sacudimiento, consistente en agitar hacia arriba el vaso de la campana, sujetándolo por los tientos enlazados en los agujeros. 
Figura 8: Mapa cultural de idiófonos andinos centromeridionales, parte 8 (véase

el Cuadro 8). Dibujos y

fotografías: M. Gudemos.

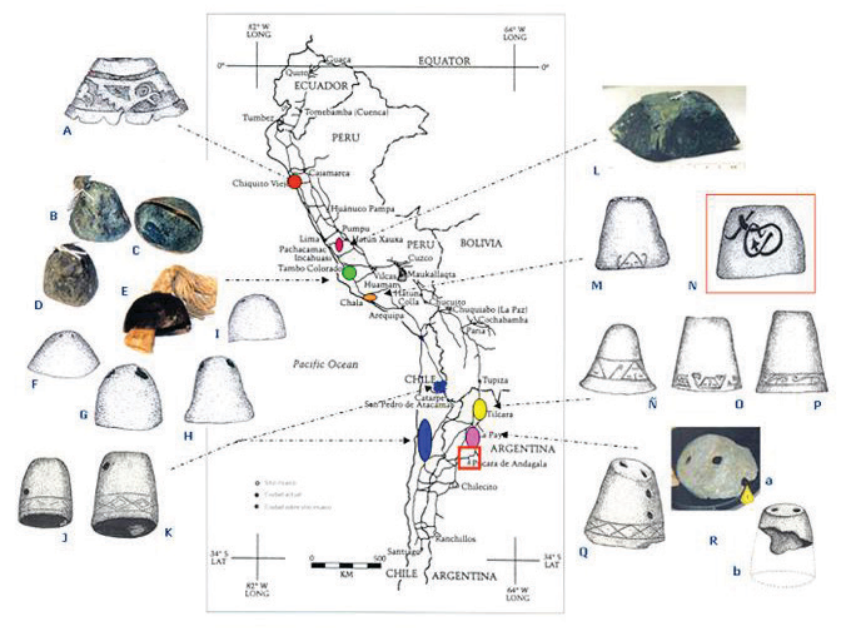

Cuadro 8: Idiófonos de la Figura 8

\begin{tabular}{|c|c|c|}
\hline Id. en fig. & Identificación y procedencia & Localización \\
\hline A & $\begin{array}{l}\text { Campanita troncocónica VA } 62232 \text { (Hacienda Casa Grande, } \\
\text { Valle de Chicama) }\end{array}$ & EM \\
\hline B & Campanita troncocónica VA 45885 (Ica) & EM \\
\hline $\mathrm{C}, \mathrm{F}$ & Campanita troncocónica VA 45887 (Ica) & EM \\
\hline $\mathrm{D}, \mathrm{G}$ & Campanita troncocónica VA 45888 (Ica) & EM \\
\hline $\mathrm{E}$ & Campanita troncocónica VA 45898 (Ica) & EM \\
\hline $\mathrm{H}$ & Campanita troncocónica VA 45884 (Ica) & EM \\
\hline I & Campanita troncocónica VA 45886 (Ica) & EM \\
\hline $\mathrm{J}, \mathrm{K}$ & $\begin{array}{l}\text { Campanitas troncocónicas (Franja regional comprendida entre } \\
\text { Caldera, Cerro del Morro y Taltal) }\end{array}$ & Latcham 1938: 323 \\
\hline $\mathrm{L}$ & Campana VA 40554 (Pachacámac) & EM \\
\hline M & Campanita troncocónica de oro $*(\mathrm{Nasca})$ & MEC \\
\hline $\mathrm{N}$ & Campanita troncocónica de cerámica * (Belén, Catamarca) & MB \\
\hline$\tilde{\mathrm{N}}$ & Campanita troncocónica № 2875 (Juella, Jujuy) & MEC \\
\hline $\mathrm{O}$ & Campanita troncocónica $\mathrm{N}^{\circ} 2873$ (Juella, Jujuy) & MEC \\
\hline $\mathrm{P}$ & Campanita troncocónica $N^{\circ} 3302$ (Angosto Chico, Jujuy) & MEC \\
\hline Q & Campanita troncocónica (Cafayate, Salta) & Aretz-Thiele 1946: 26 \\
\hline $\mathrm{R} a, \mathrm{~b}$ & Campanita troncocónica VC 4648, fragmento (Salta) & EM \\
\hline
\end{tabular}

\section{Puntos de contacto, 2}

Si bien la sección oval de estas campanas es una característica organológica local, la tipología santamaría está relacionada estilísticamente con las pequeñas campanas troncocónicas trasandinas de bronce, que Latcham (1938) denominó oportunamente cencerros (Figura 8 y Cuadro 8: J, K, Q, R). Estos ejemplares chilenos habrían tenido su eje de producción y dispersión en la franja regional comprendida entre Caldera, Cerro del Morro y Taltal, lo que explicaría el hallazgo de estos ejemplares en el NOA, entre los $25^{\circ}$ y $27^{\circ}$. Latcham (1938: 306) publica el análisis de un cencerro procedente de 


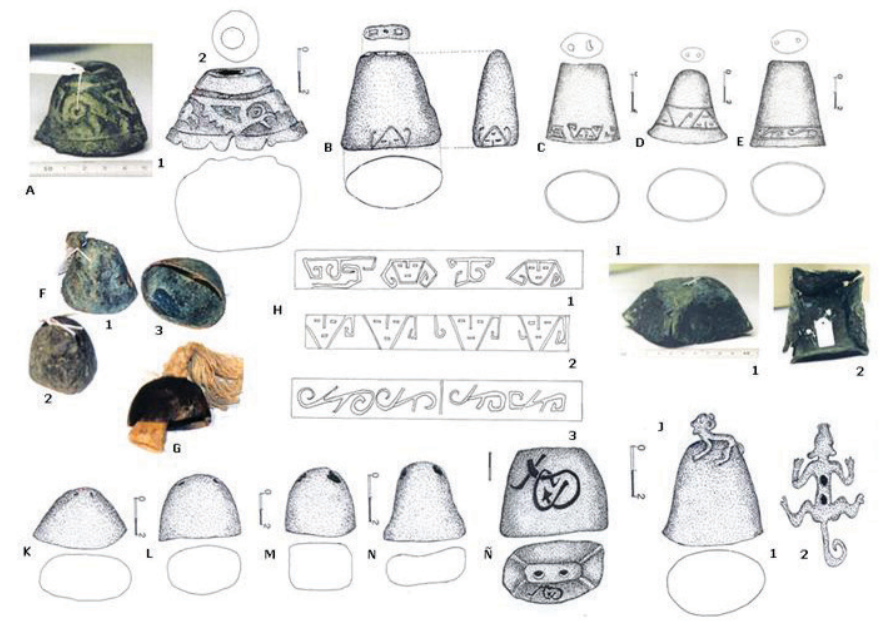

Figura 9: Mapa cultural de idiófonos andinos centromeridionales, parte 9 (véase el Cuadro 9). Dibujos y fotografías: M. Gudemos.

Cuadro 9: Idiófonos de la Figura 9

\begin{tabular}{|c|c|c|}
\hline Id. en fig. & Identificación y procedencia & Localización \\
\hline A & Campanita troncocónica VA 62232 (Hacienda Casa Grande, Valle de Chicama) & EM \\
\hline B & Campanita troncocónica de oro * (Nasca) & MEC \\
\hline $\mathrm{C}$ & Campanita troncocónica $\mathrm{N}^{\circ} 2875$ (Juella, Jujuy) & MEC \\
\hline $\mathrm{D}$ & Campanita troncocónica $N^{\circ} 2873$ (Juella, Jujuy) & MEC \\
\hline E & Campanita troncocónica $\mathrm{N}^{\circ} 3302$ (Angosto Chico, Jujuy) & MEC \\
\hline $\mathrm{F} 1, \mathrm{~J}$ & Campanita troncocónica VA 45885 (Ica) & EM \\
\hline $\mathrm{F} 2, \mathrm{M}$ & Campanita troncocónica VA 45887 (Ica) & EM \\
\hline $\mathrm{F} 3, \mathrm{~K}$ & Campanita troncocónica VA 45888 (Ica) & EM \\
\hline G & Campanita troncocónica VA 45898 (Ica) & EM \\
\hline H 1, 2, 3 & Detalles iconográficos de los ejemplares C, D, E, respectivamente. & MEC \\
\hline I & Campana VA 40554 (Pachacámac) & EM \\
\hline $\mathrm{L}$ & Campanita troncocónica VA 45886 (Ica) & EM \\
\hline $\mathrm{N}$ & Campanita troncocónica VA 45884 (Ica) & EM \\
\hline$\tilde{\mathrm{N}}$ & Campanita troncocónica de cerámica * (Belén, Catamarca) & MB \\
\hline
\end{tabular}

* Sin número de identificación en el momento del registro efectuado en esta investigación.

Conchi ${ }^{14}$, lamentablemente sin mayores datos. Con respecto a las cuatro campanillas troncocónicas halladas en territorio atacameño, este autor considera que serían de «fabricación diaguita» y que su presencia en la región se debería al comercio de intercambio (Latcham 1938: 323). Por nuestra parte, consideramos que aún es necesario profundizar en el estudio de estos objetos sonoros en forma específica para realizar determinaciones más precisas sobre posibles lugares de producción, ya que los «circuitos de movilidad» de estas pequeñas campanas troncocónicas no serían los mismos ni responderían a iguales estrategias sociales que los descritos por la movilidad de las campanillas piramidales (Gudemos ms.). Estudios más recientes (Agüero 2005; Núñez 2006; Salazar et al. 2011, entre otros) han promovido la formulación de interrogantes a partir de nuevos datos, que nos permiten «ajustar» la enunciación de hipótesis al res-

$1488,20 \% \mathrm{Cu} ; 3,18 \% \mathrm{Sn}$. 
Figura 10: Mapa cultural de idiófonos andinos centromeridionales, parte 10 (véase el Cuadro 10). Fotografías de la derecha: Schindler 2000: 216, 214, 212, 240 (reproducidas con autorización del autor); dibujos y resto de las fotografías: M. Gudemos.

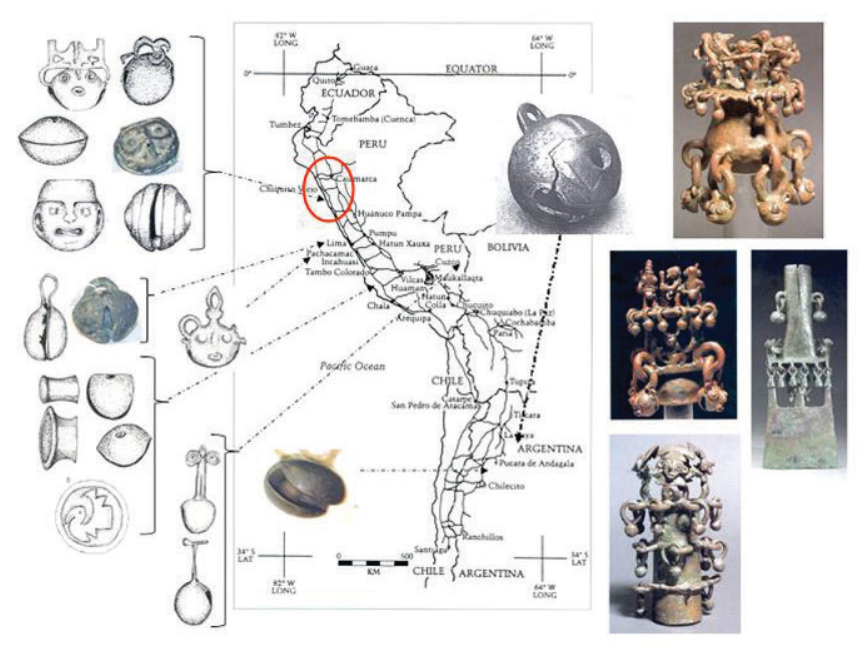

Cuadro 10: Idiófonos de la Figura 10

\begin{tabular}{|c|c|c|}
\hline Id. en fig. & Identificación y procedencia & Localización \\
\hline Derecha & $\begin{array}{l}\text { Sonaja de remate de bastón NM } 252 \text { (Costa Norte de Perú). } \\
\text { Foto en Schindler 2000: } 216\end{array}$ & MVM \\
\hline Derecha & $\begin{array}{l}\text { Sonaja de remate de bastón NM } 251 \text { (Costa Norte de Perú). } \\
\text { Foto en Schindler 2000: } 214\end{array}$ & MVM \\
\hline Derecha & $\begin{array}{l}\text { Sonaja de remate de bastón NM } 057 \text { (Costa Norte de Perú). } \\
\text { Foto en Schindler 2000: } 212\end{array}$ & MVM \\
\hline Derecha & $\begin{array}{l}\text { Sonaja de pala ceremonial NM } 250 \text { (Costa Norte de Perú). } \\
\text { Foto en Schindler 2000: } 240\end{array}$ & MVM \\
\hline Izquierda & Cascabeles. Detalles en la Figura 11 & \\
\hline Centro arriba & Cascabel N 736 S3/V4 (Quilmes) & MEC \\
\hline Centro abajo & Cascabel VC 10968 (Río del Inca) & EM \\
\hline
\end{tabular}

pecto. No obstante la relación estilística observada, estas campanitas procedentes del centro-norte chileno poseen un rasgo distintivo con respecto a las del NOA: una o más perforaciones laterales, no correspondientes a las propias de suspensión, que perjudican acústicamente su función como objeto sonoro. Tal vez, esta particularidad se deba a procesos de fabricación o a razones funcionales aún no establecidas. Latcham (1938: 233) observa, asimismo, que los cencerros atacameños se diferencian de los argentinos por su sección circular, en vez de ovalada o elíptica. Al respecto, si comparamos las procedentes de Chile, por ejemplo, con la campanita troncocónica de la Colección Moreno, procedente de Tinogasta (Catamarca), cuyo análisis ${ }^{15}$ publicó Sánchez en 1909 (fig. 19, pág. 99), se observa una clara «diferencia de línea» tanto por la sección oval de esta última, típica santamaría, como por la ausencia de las perforaciones laterales. Una tipología semejante, aunque con características morfológicas y estilísticas más próximas a las procedentes de la costa centro-sur peruana, ha sido localizada en la Quebrada de Humahuaca, más precisamente en los sitios de Juella y Angosto Chico (Figura 8

$1595,09 \% \mathrm{Cu} ; 4,84 \% \mathrm{Sn}$. 


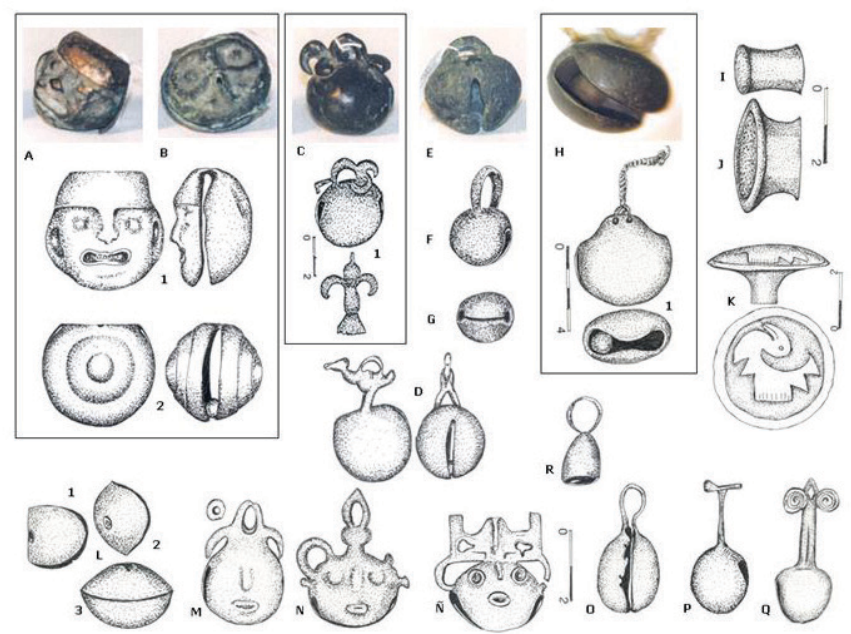

Figura 11: Mapa cultural de idiófonos andinos centromeridionales, parte 11 (véase el Cuadro 11). Dibujos y fotografías: M. Gudemos.

Cuadro 11: Idiófonos de la Figura 11

\begin{tabular}{lll}
\hline Id. en fig. & \multicolumn{1}{c}{ Identificación y procedencia } & Localización \\
\hline A & Cascabel VA 40694 (Pachacámac). Morfología de amplia difusión & EM \\
B & Cascabel VA 31123 (Trujillo). Morfología de amplia difusión & EM \\
1 & Cascabel NM 104 (Costa Norte de Perú, s/Schindler 2000: 220) & MVM \\
2 & Cascabel NM167 (Costa Norte de Perú, s/Schindler 2000:193) & MVM \\
C, 1 & Cascabel VA 21805 (Trujillo) & EM \\
D & Cascabel NM 103 (Costa Norte de Perú, s/Schindler 2000: 220) & MVM \\
E & Cascabel VA 26293 (Lima) & EM \\
F, G, R & Cascabeles NM 248 (Costa Norte de Perú). Morfologías de amplia difusión & MVM \\
H, 1 & Cascabel VC 10968 (Río del Inca) & EM \\
I & Orejera sonaja VA 45725 (Ica) & EM \\
J & Orejera sonaja VA 45738 (Ica) & EM \\
K & Orejera sonaja VA 45759 (Ica) & EM \\
L 1 & Cascabel VA 45890 (Ica). Morfología de amplia difusión & EM \\
L 2 & Cascabel VA 45891 (Ica). Morfología de amplia difusión & EM \\
L 3 & Cascabel VA 2395 (Casma-Huaraz). Morfología de amplia difusión & EM \\
M & Cascabel VA 25181 (Chuquitanta) y detalle del cuerpo metálico de sacu- & EM \\
& dimiento que se halla en su interior & \\
N & Cascabel VA 27007 (Pachacámac) & EM \\
$\tilde{N}$ & Cascabel VA 21866 (Trujillo) & EM \\
O & Cascabel VA 26295 (Lima) & EM \\
P & Cascabel VA 8785 (Cusco) & EM \\
Q & Cascabel VA 8783 (Cusco) & EM \\
\hline
\end{tabular}

y Cuadro 8: Ñ, O, P) en Fase Pukara, según cronología propuesta por Nielsen (1997: 112). La boca evertida de una de las campanitas procedentes de Juella constituiría un indicativo cierto de su ascendencia o influencia cultural foránea, lo que no significa que no sea de factura local, como los otros dos ejemplares. A propósito, la campanilla troncocónica procedente del sitio Los Amarillos (1300-1430 d.C.), cuya línea estilística es muy parecida a la de Angosto Chico, sería de factura local (Angiorama 2011: fig. 3). No 
olvidemos, como ya tratamos en otra ocasión (Gudemos 1998a: 23-24), que en Pucará de Tilcara se habrían hallado núcleos interiores como los utilizados para la manufactura de objetos metálicos huecos como éstos. Líneas de diseño semejantes se han observado también en idiófonos de tradición surperuana, como vemos en el ejemplar Nasca de oro de la Figura 8:M (ver también Cuadro 8: M). Por su parte, un ejemplar arqueológico aislado de cerámica, formalmente semejante, procedente de Belén (Catamarca) constituye una interesante rareza (Figura 8 y Cuadro 8: N).

Emparentadas morfológicamente con éstas, pero con una línea de «base de vaso» diferente, las campanitas troncocónicas de cobre de Ica del Periodo Intermedio Tardío (ca. 900-1470 d.C.) ${ }^{16}$ presentan una regularidad formal característica. Pertenecen a una tradición tecnológica local con conocimiento de principios acústicos específicos. En el caso de vaso simple (sin decoración de tipo escultórico), sólo éste fue fundido; las perforaciones fueron practicadas por impacto desde adentro (Figura 8 y Cuadro 8: B; Figura 9 y Cuadro 9: F 1, J). Otras fueron fundidas en su totalidad. Entre ellas, registramos solo un ejemplar de bronce arsenical (Figura 8 y Cuadro 8: E; Figura 9 y Cuadro 9: G).

\section{La belleza de la variedad}

La gran variedad estilística y tecnológica de sonajeros ${ }^{17}$, sonajas, cascabeles y tamborcillos de metal en el mundo andino constituye el más fiel reflejo de la importancia social que tuvieron estos objetos. Color, brillo, diseño, funcionalidad; juegos de luz, sonido y movimiento. Todas las técnicas metalúrgicas conocidas en tiempos prehispánicos fueron aplicadas en su fabricación: planchas repujadas y plegadas, fundidas y plegadas; con o sin soldaduras, vasos de sonajeros fundidos, de cobre, plata, oro, bronce, etc. La imaginación creadora se aplicó en todos los órdenes. Así, individualizamos la inconfundible línea cusqueña de cascabeles y campanillas, con una compleja asimilación estilística de rasgos plásticos de tradiciones TiahuanacoHuari, Huari costeño y Chimú, principalmente. En la Costa Central de Perú, en los idiófonos de procedencia Pachacámac por ejemplo, la fuerte impronta tecnológica moche se observa asimilada con el sustrato de la tradición estilística de los idiófonos de la Costa Sur. Por su parte, la tecnología chimú, heredera cultural de la tradición metalúrgica moche, constituyó el antecedente cultural más importante, difundido y asimilado ampliamente en el mundo andino. Su alta producción de sonajas compuestas de excepcional calidad para palas y bastones ceremoniales es realmente notable (Figura 10, derecha). Cuchillos con cuerpo sonaja son propios de la costa norte peruana (de ascendencia cultural Lambayeque y Moche, principalmente), pero de amplia trascendencia espacio-temporal. Protectores de armadura repujados, boleadoras sonajero fundidas de gran tamaño son propios del estilo Costa Norte con ascendencia cultural Chimú (Gudemos ms.). Asimismo, se destacaron los pequeños tambores de cobre que, entre los incas, eran muy propios de la práctica musical de las mujeres de

16 En acuerdo con Schindler 2000.

17 Taxonomía numérica 112.13: idiófonos de sacudimiento o sonajas de vaso (cascabeles y sonajeros). 
élite (Gudemos 2004). En el NOA se observa, sin embargo, una significativa falta de estos objetos fabricados en metal. Sólo dos ejemplares aislados, fundidos de bronce, procedentes de Río del Inca y Quilmes, respectivamente, fueron inventariados como prehispánicos. Pero sólo del ejemplar de Río del Inca (Figura 11 y Cuadro 11: H) tenemos datos contextuales prehispánicos a través de los manuscritos de Max Uhle (Legado Max Uhle, Cuaderno 30, pp. 198-200; Gudemos 2006: 249-250). Mientras que el de Quilmes, creemos, sería de factura hispánica o colonial. Recién en los ajuares hispano-indígenas, principalmente en la Quebrada de Humahuaca, como vimos, aparecen cascabeles metálicos sencillos (dos secciones semiesféricas soldadas o embutidas), que creemos son de ascendencia cultural foránea, fabricados con técnicas mixtas: fundición y forja, unión en estado sólido y con la incorporación de la soldadura con aporte de material (De Rosa et al. 2008). Según nuestros estudios, es posible que estos objetos, generalmente piezas de arneses y en muchos casos de ascendencia cultural hispano-árabe ${ }^{18}$, hubieran tenido una amplia circulación en la Quebrada de Humahuaca como elementos de regalía entre personajes de élite, incluso antes del ingreso efectivo de los europeos en la región. No descartamos por ello que no existiese una factura local de estos idiófonos, pero aún no contamos con datos puntuales al respecto.

\section{Consideraciones finales}

Tras estos breves datos, cabe decir que, en Arqueomusicología, la comprensión cultural del material centraliza la totalidad de las actividades técnicas, desde la clasificación taxonómica y el estudio de técnicas constructivas metalográficas, como en este caso, hasta el estudio social de las posibles vías interregionales de comunicación y de la asimilación cultural de patrones sonoros en determinadas organologías. El análisis sistemático de los emergentes materiales del mal llamado patrimonio inmaterial es el primer paso para la comprensión de la cultura musical de los pueblos.

Agradecimientos: Este trabajo se realizó en el marco del Proyecto en Arqueomusicología Americana radicado en el CIFFyH, UNC: Mapa cultural de la música prehispánica en América Andina con fondos SeCyT. Agradezco a todas y cada una de las instituciones que me permitieron registrar y estudiar los materiales arqueológicos aquí tratados y las fuentes documentales manuscritas a ellos vinculadas. Extiendo mi agradecimiento al Servicio Alemán de Intercambio Académico (DAAD) por financiar gran parte de mis investigaciones en Alemania, al Dr. Gregor Wolff (Instituto Ibero-Americano de Berlín) por su colaboración durante mis estancias de investigación sobre el Legado Max Uhle, al Dr. Luis González por sus comentarios sobre este trabajo en el marco del Simposio «Acercamientos arqueológicos e históricos a la antigua minería y metalurgia surandina» (Congreso Nacional de Arqueología Argentina, 2010) y a la Dra. María Jesús Jiménez Díaz por solicitármelo para su publicación en este volumen.

18 En América habrían ingresado durante la conquista dos tipos de monturas: la estradiota y bridona (estilo centro europeo a la brida) y, principalmente, la típica jineta (de estilo árabe o a la jineta) con bordes de «anqueras» con cascabeles. De ambos tipos surgiría en tierras americanas la colonial española a la bastarda. Véase, entre otros, Flores Hernández 1997. 


\section{Siglas utilizadas}

[EM]: Ethnologisches Museum. Berlín.

[MEC]: Museo Dr. Eduardo Casanova. Tilcara. Jujuy.

[MB]: Museo de Belén. Catamarca.

[MVM]: Museum für Völkerkunde. Munich.

[MGLP]: Museo Gustavo Le Paige. San Pedro de Atacama.

[MAQ]: Museo Adán Quiroga. Catamarca.

[MLP]: Museo de La Plata.

\section{Referencia documental}

Legado Max Uhle, Cuaderno 30

Nachlass Max Uhle, Notizbuch n 30 (2 Febr.-30 April 1893). Ibero-Amerikanisches Institut Preußischer Kulturbesitz, Berlín. Signatura: N-0035 w 266.

\section{Referencias bibliográficas}

AgüERo, Carolina

2005 «Aproximación al asentamiento humano temprano en los oasis de San Pedro de Atacama». Estudios Atacameños 30: 29-60.

AmbrosetTi, Juan

1904 «El bronce en la Región Calchaquí». Anales del Museo de Ciencias Naturales de Buenos Aires 11, Serie III, Tomo IV: 163-312.

Angiorama, Carlos I.

2011 «Impacto de la conquista inca en la metalurgia de Los Amarillos (Quebrada de Humahuaca, Jujuy)». Andes [online] 22 (1). http://www.scielo.org.ar/scielo.php?script $=$ sci_arttext\&pid $=\mathrm{S} 1668-80902011000100001>$, con acceso el $11 / 10 / 2012$.

ARELlano LóPEZ, Jorge

1982 «Algunos aportes al comportamiento de la metalurgia prehispánica en Bolivia». Bulletin de l'Institut Français d'Études Andines 11 (3-4): 79-90.

BOMAN, Eric

1992 Antigüedades de la región andina de la República Argentina y del desierto de Atacama [1908]. Jujuy: Universidad Nacional de Jujuy.

De Rosa, Horacio, Geraldine Gluzman, Luis González y Hernán Svoboda

2008 «Caracterización de fragmentos de cascabel del Noroeste de Argentina». Ponencia presentada en el $8^{\circ}$ Congreso de Metalurgia CONAMET/SAM, Santiago de Chile, 28-31 de octubre. http://www.materiales-sam.org.ar/sitio/biblioteca/CONAMETSAM2008/pdfs/m1.pdf, con acceso el 15/9/2013.

FLORES HeRnández, Benjamín

1997 «La jineta indiana en los textos de Juan Suárez de Peralta y Bernardo de Vargas Machuca». Anuario de Estudios Americanos 54 (2): 639-664.

GonZÁLEZ, Alberto Rex

1979 «Pre-Columbian Metallurgy of Northwest Argentina: Historical Development and 
Cultural Process», en Pre-Columbian Metallurgy of South America, Elizabeth Benson, ed., pp. 133-202. Washington: Dumbarton Oaks.

GonZÁLEZ, Luis

2007 «Tradición tecnológica y tradición expresiva en la metalurgia prehispánica del Noroeste Argentino». Boletín del Museo Chileno de Arte Precolombino 12 (2): $33-48$.

GonZÁlez, Luis y Héctor BuONO

2007 «Hachas y cetros de metal del Noroeste Argentino prehispánico». Revista Andina 44: 175-198.

Graffam, Gray, Álvaro CAREvic y Mario Rivera

1997 «Evidencias de fundición de cobre en el sitio formativo tardío de Ramaditas, quebrada de Guatacondo, Provincia de Iquique, Chile». Estudios Atacameños 12: 4759.

Gudemos, Mónica

1998a Antiguos sonidos. Jujuy: Instituto Interdisciplinario Tilcara, Universidad de Buenos Aires.

1998b «Campanas arqueológicas de metal del Noroeste Argentino». Anales del Museo de América 6: 111-146.

2001 La música como emblema de poder en los andes centro-meridionales. Estudios en arqueomusicología para América Andina. Tesis Doctoral. Universidad Complutense de Madrid.

2004 Canto, danza y libación en los Andes. La música en los queros del Museo de América. Madrid: Ministerio de Cultura.

2006 «Los estudios en arqueomusicología americana y la información de Max Uhle en sus notas manuscritas». Indiana 23: 229-282.

ms. «Proyecto en Arqueomusicología americana: Mapa cultural de la música prehispánica en América Andina». SeCyT, Proyecto a/2012.

LATCHAM, Ricardo E.

1938 Arqueología de la Región Atacameña. Santiago de Chile: Prensas de la Universidad de Chile.

Llagostera, Agustín

1996 «San Pedro de Atacama: nodo de complementariedad reticular», en La integración sur andina cinco siglos después, X. Albó, M. I. Arratia, J. Hidalgo, L. Núñez, A. Llagostera, M. I. Remy y B. Revesz, eds., pp. 17-42. Cuzco: Centro de Estudios Regionales Andinos «Bartolomé de Las Casas».

NiELSEN, Axel

1997 Tiempo y cultura material en la Quebrada de Humahuaca 700-1650 d. C. Jujuy: Instituto Interdisciplinario Tilcara, Universidad de Buenos Aires.

NúÑEZ, Lautaro

2005 «La naturaleza de la expansión aldeana durante el Formativo Tardío en la Cuenca de Atacama». Chungara 37 (2): 165-193.

2006 «La orientación minero-metalúrgica de la producción atacameña y sus relaciones fronterizas», en Esferas de interacción prehistóricas y fronteras nacionales modernas: los Andes sur-centrales, H. Lechtman, ed., pp. 205-260. Lima: Instituto de Estudios Peruanos. 
Salazar, Diego, Valentina Figueroa, Diego Morata, Benoit Milleiv, Germán Manríquez y Ariadna CIFUENTES

2011 «Metalurgia en San Pedro de Atacama durante el Período Medio: nuevos datos, nuevas preguntas». Revista de Antropología 23: 123-148.

SÁnCHEZ, Abel

1909 Aleaciones. El bronce calchaquí. Tesis doctoral. Universidad Nacional de Buenos Aires.

SCHINDLER, Helmut

2000 Die Kunstsammlung Norbert Mayrock aus Al-Peru. Munich: Staatliches Museum für Völkerkunde.

TARRAGÓ, Myriam

2006 «Espacios surandinos y la circulación de bienes en época Tiwanaku», en Esferas de interacción prehistóricas y fronteras nacionales modernas: los Andes surcentrales, H. Lechtman, ed., pp. 331-376. Lima-Nueva York: Instituto de Estudios Peruanos - Institute of Andean Research. 